\title{
Morphological Analysis of Length of Human Humerus
}

\author{
Meghana N. ${ }^{1}$, P. Savithri ${ }^{2}$ \\ ${ }^{1}$ Department of Anatomy, Guntur Medical College, Guntur, Andhra Pradesh, India. \\ 2Department of Anatomy, Guntur Medical College, Guntur, Andhra Pradesh, India.
}

\section{ABSTRACT}

\section{BACKGROUND}

Estimating the height plays an important role in identifying unknown bodies. For that, the length of long bones is taken into consideration. This kind of study helps forensic, anatomical, and archaeological cases. It is also useful to orthopaedic surgeons for treatment of proximal and distal humeral fractures, and also for their reconstruction. It is also important in identification of missing persons in medicolegal investigations to define identity of skeleton. Estimation of length of long bones enables quantification of bones, and internal mechanical properties as a possible way to improve the assessment of asymmetry in the humerus. Humerus is a long bone in the upper limb that articulates with scapula at glenohumeral joint and radius and ulna at elbow joint. We wanted to determine the length of humerus and establish a relation between right and left humeri.

\section{METHODS}

The current study is conducted to determine the length of humerus in a total of 40 humeri (20 right and 20 left) collected from the Department of Anatomy, Guntur Medical College, Guntur. Each humerus is measured using an osteometric board.

\section{RESULTS}

Results are tabulated as mean and standard deviation, and statistically compared between right and left humeri. The right humeri are comparatively bigger than the left humeri. Further results correlated with previous studies. The mean length of the right humerus was 30.05 with the standard deviation 2.339 .

\section{CONCLUSIONS}

Humeral length shows a great variation. Asymmetry between right and left humerus should be considered to be hereditary. In many situations the full length of long bones may not be available. In such cases it was confirmed by classical osteometric techniques in which humerus even in fragmented state can be recorded in a forensic case.

\section{KEY WORDS}

Humerus, Total length, Reconstruction, Asymmetry, Implants, Handedness
Corresponding Author:

Meghana N.,

D. No. 1-63/3,

Opposite Ladies Polytechnic College,

Chowdari Pet, Near Mehta's Plaza,

Guntur-522006, Andhra Pradesh, India.

E-mail:meghana.niny@gmail.com

DOI: $10.14260 /$ jemds/2020/422

How to Cite This Article:

Meghana N, Savithri P. Morphological analysis of length of human humerus. J. Evolution Med. Dent. Sci. 2020;9(27): 1940-1943, DOI:

$10.14260 /$ jemds $/ 2020 / 422$

Submission 20-08-2019,

Peer Review 03-06-2020

Acceptance 10-06-2020,

Published 06-07-2020.

Copyright (C) 2020 JEMDS. This is an open access article distributed under Creative Commons Attribution License [Attribution 4.0 International (CC BY 4.0)] 


\section{BACKGROUND}

Estimating height of the individual plays a vital role in identifying unknown bodies. For that, the length of long bones is taken into consideration. This kind of study helps forensic, anatomic, and archaeological cases as well as for orthopaedic surgeons for treatment of proximal and distal humeral fractures and their reconstruction. It is also crucial in the identification of missing persons in medicolegal investigations (Ross \& Konigsberg, 2002; Wright \& Vasquez, 2003),(1) to define the identity of the skeleton.

A frequently cited characteristic of the human species, the concept of handedness represents a persistently mysterious notion in modern society. Although important because the development of both handedness and language can be attributed to cerebral hemispheric lateralization in our past, this feature remains ill-defined and is challenging. Estimation of length of long bones enables quantification of bones internal mechanical properties as a possible way to improve the assessment of asymmetry in the humerus.

Symmetry is defined as correspondence in size, shape and relative position of parts on opposite sides of a dividing line or median plane while asymmetry is described as a lack or absence of symmetry. (Zaidi 2011).(2) Several studies have established a relationship between morphological and behavioural asymmetry making investigations of bilateral bone asymmetry an attractive and important research area.(3) This field may help to understand how behaviour can influence the dynamic development of bone structure. Bone asymmetry is thought to basically results from disproportionate mechanical stress which influences bone remodelling and plasticity [Trinkaus (4) et al. 1994; Churchill and Formicola 1997].(5)

The humerus, the longest and largest bone in the upper limb, has expanded ends and a shaft. The high end of the humerus consists of the head, anatomical neck, and the greater and lesser tubercles. It joins the shaft at an ill-defined 'surgical neck'. The head is directed medially, backwards and upwards to articulate with the glenoid cavity of the scapula. The anatomical neck of the humerus, a slight constriction, immediately adjoins the margin of the head, the lesser tubercle is distal to the anatomical neck. The greater tubercle is the most lateral part of the proximal end of the humerus. The shaft has three surfaces -the posterior surface, the anterolateral and the anteromedial surfaces. It also has three borders-the anterior, the lateral, and the medial borders. The distal end of the humerus is a modified condyle and has articular and non-articular parts. The articular part is divided by a faint groove into a lateral capitulum and a medial trochlea. It articulates with the radius and the ulna at the elbow joint. The non-articular part of the condyle includes the medial and lateral epicondyles, and the olecranon, coronoid and radial fossae.(6)

\section{Objectives}

1. To determine the length of the humerus.

2. To establish a relation between right and left humeri

3. To compare the obtained values with that of other studies.

\section{METHODS}

The Present study estimates the average length of the humerus in a total of 40 unpaired adult dry humeri $(20$ belonging to right and 20 belonging to left). We collected the bones from skeletal sets for medical students in the department of anatomy, Guntur Medical College, Guntur. Each humerus is measured using an osteometric board.

\section{Inclusion Criteria}

Humeri in good condition irrespective of age, individual, cause of death included in the study.

\section{Exclusion Criteria}

Damaged, diseased, and incomplete bones not included in this study.

\section{Statistical Analysis}

The following methods of statistical analysis have been used in this study. The results as averaged as mean, standard deviation to statistically compare between right and left humeri. The data was analyzed using SPSS version 20. One sample -t-test was used to determine whether the difference between the two means is statistically significant or occurred by chance.

\section{RESULTS}

We tabulated results as mean, standard deviation, and standard error of mean to statistically compare between right and left humeri. All measurements are taken in centimetres. The humeral length was taken as the distance between the most proximal point of the head of humerus to the most distal point of the trochlea.

The mean length of the right humerus was 30.05 with the standard deviation 2.339 and standard error of mean 0.523 respectively. More, the minimum value of the length of the right humerus was 25, the maximum value of length was 33 .

On the other hand, the mean length of the left humerus was 29.5 with a standard deviation of 2.139 and standard error of mean 0.478 respectively. Conversely, the minimum values of length of the left humerus were 24.5 , the maximum value of length was 32.5 .

A comparison between length of right and left humeri revealed a significant statistical difference ( $\mathrm{p}$-value $0.000, \mathrm{t}$ test value $=84.439$ )

\begin{tabular}{|ccc|}
\hline Result & Left Humeri (n=20) & Right Humeri (n=20) \\
Mean Total Length & 29.5 & 30.05 \\
Standard Deviation & 2.139 & 2.339 \\
Standard Error of the mean & 0.478 & 0.523 \\
\hline \multicolumn{2}{|c|}{ Table 1. Comparison between Left and Right Humeri } \\
\hline
\end{tabular}




\section{DISCUSSION}

This study correlates with the research made by $\mathrm{S}$. Deniz.(7)and papalaucas et al in the year 2005 on Caucasian humeri of the Turkish population in which they found mean length of the right humerus was greater than left. This study correlates with the study made Lakshmi Kantham B.M. B.G.S Global Institute of medical sciences Kangri, Bangalore, India(8)on 150 dry humeri from M. S. Ramaiah Medical College, Bangalore in which they found the mean length of the right humerus was greater than left. This study correlates with a study made by Phalguni Srimani, Madhumita Datta, Ankana Saha and Sibani Mazumdar (9)in 2017 where they used 60 unpaired adult dry humeri ( 30 belonging to right and 30 belonging to left) of unknown age and sex. This study correlates with a study made by S.D. Desai,(10) Hussain Saheb Shaik Department of Anatomy, Shri BM Patil Medical College, Bijapur, Karnataka, JJM Medical College, Davangere, Karnataka over a total of 90 humeri (52 right and 38 were left)This study varies with the research conducted by Shilpa K et al.(11) on south Indian population in Mangalore region it was found that on the right side mean total length of humeri was lesser but on the left side mean total length of humeri was more.

\begin{tabular}{|ccc|}
\hline $\begin{array}{c}\text { Name of the } \\
\text { Author }\end{array}$ & $\begin{array}{c}\text { Mean Total Length } \\
\text { of Right Humeri }\end{array}$ & $\begin{array}{c}\text { Mean Total Length } \\
\text { of Left Humeri }\end{array}$ \\
S. Deniz Akman et al ${ }^{7}$ & $307.1 \pm 20.8$ & $304.8 \pm 18.9$ \\
Lakshmi Kantha B.M $^{8}$ & $306.19 \pm 18.02$ & $303.91 \pm 19.28$ \\
S.D Desai, Hussain Saheb Shaik ${ }^{9}$ & $292.3 \pm 22.9$ & $289.45 \pm 21.8$ \\
Phalguni Srimani et al ${ }^{10}$ & $307.3 \pm 17.99$ & $297.77 \pm 19.78(\mathrm{p}=0.06)$ \\
Shilpa K et al ${ }^{11}$ & $309.6 \pm 20.6$ & $299.6 \pm 22.5$ \\
Present study & $30.05 \pm 2.33$ & $29.5 \pm 2.13$ \\
\hline \multicolumn{2}{|c|}{ Table 2. Comparison between Various Studies } \\
\hline
\end{tabular}

Humeral maximum length asymmetry should, therefore, be regarded as an expression of congenital asymmetry. However, asymmetries that are not congenital in origin also occur. Previous studies attempted to confirm the factors that affect the long bone dimensions and to explain the phenomenon of difference in length between the right and left humerus. One of a possible explanation for the humerus asymmetry is the handedness. (Schulter- Ellis, 1980,(12) Schell et al., 1985; Vettivel et al., 1992, 1995; Scheuer and Black, 2007).(13)

Handedness, as a behaviour defined as the constant use of a 'dominant' limb over the other during bimanual activities, denotes an asymmetric increase in the mechanical load of the preferred limb. According to the principle of bone functional adaptation, bone undergoes changes itself in response to mechanical stress in a interplay of osteolytic bone resorption and apposition by osteoblast action; this production of new bone reduces strain by increasing bone strength, leaving behind at death asymmetric skeletal elements indicative of bilateral mechanical loading (Steele, 2000; Chen et al., 2010; Ruff et al., 2006; Ruff, 2008).(14)

Many researchers have been supported for about two centuries (Arnold, 1844; Gennadis, 1858),(15) that this asymmetry it is most likely possible to be inherited (Schultz, 1926, 1937;(16) Pande and Singh,1971; Singh, 1971;(17) Vettivel et al., 1995; Scheuer and Black, 2007), neurophysiological (White et al., 1994,(18) Steel and Mays, $1995)^{(19)}$ or solely acquired. Pande and Singh (1971), to give evidence that the phenomenon of asymmetry is inherited, they studied in fetuses the weight of muscles and bones of the upper extremity. They emphasized that the total muscle and bone weight was greater on the right side in 9 of 10 fetuses $(p<0.001)$, which proves that the individual inherits heavier stronger muscles and bones in the dominant limb (Singh, 1971).

Apart from the inheritance, other factors such as mechanical loading on an adult's arm or disuse of one arm may influence the asymmetry. (Singh, 1971; Steel and Mays, 1955).Environmental factors like trauma or toxins in fetal or early life may exhibit influence on the asymmetry. (Pande and Singh, 1971; Le May 1992.(20) Protein deficiency decreases the asymmetry (Steyn and Iscan, 1999; Mall et al., 2001).(21)On the contrary, sports games, professional or habitual activities use which non - dominant limb, may alter the asymmetry between the right and left humerus (Stirland, 1993).(22) Activities taken equally by two hands may result in lack of asymmetry as it was noticed to the Mary Rose Males(23) (Rule, 1982; Stirland, 1993).

Mary Rose was King Henry's the 8th flagship which sank on 19th July 1545 with loss of most of its 415 crew. The ship was filled and sealed quickly. This process produced an anaerobic environment, enabled to maintain the human bones, for almost five centuries, in excellent condition. The excellent condition of the bones allowed the measurements of the paired humeri, and the work every man was doing on the ship was defined. As it was known, considering the equipment excavated, on board there were many of the best professional archers and they were found from the lack of asymmetry between the right and left humerus because the length of the left arm had been enhanced by the continuous use of the medieval heavy longbow.

\section{CONCLUSIONS}

Humeral length shows a great variation which is likely to be due to factors such as nature of work, mode of life, continuous modifications that may affect the characteristics of man as well as effects of civilization on composition of human body.(24) Asymmetry between right and left humerus as it has been maintained by old and modern researchers, must be considered inherited. It can be enhanced or reduced according to individuals' habits and activities, age, nutrition, overuse or disuse of the limb. The study is used to add as reference to other studies which are aimed to determine location of nutrient foramen. In many situations the full length of long bones may not be available. In such cases it was confirmed by classical osteometric techniques in which humerus even in fragmented state can be recorded in a forensic case.(25) The mean value of the total humerus length gives important evidence to indicate the characteristic features of an individual.(26-27) 


\section{REFERENCES}

[1] Ross AH, Konigsberg, LW. New formulae for estimating stature in the Balkans. J Forensic Sci2002;47(1):165-7.

[2] Zaidi ZF. Body asymmetries: incidence, etiology and clinical implications. Australian Journal of Basic and Applied Sciences 2011;5(9):2157-91.

[3] Lazenby RA. Skeletal biology, functional asymmetry and the origins of "Handedness". Journal of Theoretical Biology 2002;218(1):129-38.

[4] Trinkaus E, Churchill SE, Ruff CB. Postcranial robusticity in homo. II: Humeral bilateral asymmetry and bone plasticity. Am J Phys Anthropol 1994;93(1):1-34.

[5] Churchill SE, Formicola V. A case of marked bilateral asymmetry in the upper limbs of an Upper Palaeolithic male from Barma Grande (Liguria) Italy. International Journal of Osteoarchaeology1997;7(1):18-38.

[6] Standring S. Humerus. In: Standring S, eds. Gray's anatomy: the anatomical basis of clinical practice. $41^{\text {st }}$ edn. London: Churchill Livingstone Elsevier 2017:804-7.

[7] Akman SD, Karakas P, Bozkir MG. The morphometric study of humerus segments. Turk J Med Sci 2005;36:815.

[8] Lakshmi Kantha BM, Kulkarni R. Estimation of a total length of the humerus from its fragments in south Indian population. Int J Anat Res 2014:2(1):213-20.

[9] Desai SD, Shaik HS. A morphometric study of humerus segments. J Pharm Sci Res 2012;4(10):1943-5.

[10] Srimani P, Datta M, Saha A, et al. Prediction of total length of humerus from its fragments in West Bengal Population. International Journal of Anatomy, Radiology and Surgery 2017;6(1):A001-6.

[11] Shilpa K, Swamy G, Somesh MS, et al. Morphometric measurements of humerus segments in the south Indian population. Proceedings of the 12th conference of Karnataka chapter of anatomists, Kolar 2010: p. 44.

[12] Schulter-Ellis FP. Evidence of handedness on documented skeletons. J Forensic Sci 1980;25(3):624-30.

[13] Cunningham C, Scheuer L, Black S, et al. Developmental juvenile osteology. $1^{\text {st }}$ edn. New York: Academic Press 2007.
[14] Steele J. Skeletal indicators of handedness. In: Cox M, Mays S, eds. Human osteology in archaeology and forensic science. Cambridge: Cambridge University Press 2000:307-24.

[15] Gennadi G. Textbook of regional anatomy $1^{\text {st }}$ edn. Athens: Antoniadis Publisher 1858:270-1.

[16] Schultz AH. Proportions, variability, and asymmetries of the long bones of the limbs and the clavicles in man and apes. Hum Biol 1937;9(3):281-328.

[17] Pande BS, Singh I. One-sided dominance in upper limbs of human fetuses as evidenced by the asymmetry in muscle and bone weight. J Anat 1971;109(Pt 3):457-9.

[18] White TD, Folkens PA. The human bone manual. $1^{\text {st }}$ edn. New York: Elsevier Academic Press 2005:52-4.

[19] Steel J, Mays S. Handedness and directional asymmetry in the long bones of the human upper limb. Int J Osteoarcheol 1995;5(1):39-49.

[20] LeMay M. Left-right dissymmetry, handedness. AJNR Am J Neuroradiol1992;13(2):493-504.

[21] Steyn M, Iscan MY. Osteometric variations in humerus: sexual dimorphism in South Africans. Forensic Sci Int 1999;106(2):77-85.

[22] Stirland AJ. Asymmetry and activity related change in the male humerus. Int J Osteoarchaeol 1993;3(2):105-13.

[23] Rule M. The Mary Rose: the excavation and raising of henry VIII's flagship. $1^{\text {st }}$ edn. Leicester: Windward 1982:26-31.

[24] Singh A, Nagar M, Kumar A. An anthropometric study of the humerus in adults. Research and Reviews: Journal of Medical and Health Sciences 2014;3(3):77-82.

[25] Papaloucas M, Papaloucas C, Tripolitsioti A, et al. The asymmetry in length between right and left humerus in humans. Pak J Biol Sci 2008;11(21):2509-12.

[26] Ozaslan A, Işcan, MY, OzaslanI, et al. Estimation of stature from body parts. Forensic Sci Int 2003;132(1):40-5.

[27] Pearson K. Mathematical contribution to the theory of evaluation. V. On the reconstruction of the stature of prehistoric races. Philosophical Trans $\mathrm{R}$ Soc Lond 1899;192:169-244. 